\title{
MMP expression alteration and MMP-1 production control by syringic acid via AP-1 mechanism
}

\author{
Ji Young Ryu ${ }^{1}$ and Eun Ju Na ${ }^{2 *}$
}

\begin{abstract}
Background: Syringic acid is a phenolic compound that can be produced through selective hydrolysis of eudesmic acid containing $20 \%$ sulfuric acid. The acid is obtained by breaking down components, such as anthocyanin and lignin acid, present in the oils of acai berries and other fruits. Recently, the anti-inflammatory, selective toxicity, anticancer, and antioxidant effects of syringic acid have been studied, but few studies on the effects of syringic acid on human keratinocytes ( $\mathrm{HaCaT}$ ) cells have been published. The present study investigated the antioxidant effects of syringic acid, as a potential cosmetic ingredient, on matrix metalloproteinase (MMP) expression alteration and MMP production control through the activator protein-1 (AP-1) mechanism in HaCaT cells exposed to ultraviolet $B$ radiation.
\end{abstract}

Methods: A reactive oxygen species (ROS)-scavenging assay using a luciferase reporter that utilizes the AP1 response element, an enzyme-linked immunosorbent assay (ELISA), and quantitative reverse transcription polymerase chain reaction (qRT-PCR) were used. To confirm if ROS in HaCaT cells damaged by ultraviolet B are eliminated by syringic acid, 2'-7'-dichlorofluorescein diacetate was used to measure the ROS quantity. qRT-PCR analysis was used to measure the expressions of SOD1 mRNA, GPX1 mRNA, and catalase (CAT) mRNA, which are related to oxidation inhibition. To measure the anti-aging effects of syringic acid, QRT-PCR was used to measure the expression levels of MMP mRNA, c-Jun, and c-Fos.

Results: ROS were eliminated by syringic acid, and cell aging due to ultraviolet B was suppressed. Results of qRTPCR analysis confirmed that syringic acid suppressed oxidation in HaCaT cells damaged by ultraviolet B. Further, syringic acid was found to suppress the expression of MMP mRNA, c-Jun, and c-Fos in a concentration-dependent manner. ELISA showed that MMP-1 production decreased in a concentration-dependent manner. The luciferase reporter analysis revealed a concentration-dependent decrease in the transcriptional activity of AP-1 promoter caused by syringic acid.

Conclusions: Syringic acid was shown to be involved in altering MMP expression and controlling MMP-1 production through the AP-1 mechanism. Thus, the antioxidant and anti-aging effects of syringic acid increased the survival rate of $\mathrm{HaCaT}$ cells damaged by ultraviolet B, suggesting that it can be used as a natural phytochemical in cosmetic products.

Keywords: Syringic acid, HaCaT, Ultraviolet B, ROS, Antioxidant, MMPs, Procollagen type I

\footnotetext{
* Correspondence: ejhk1010@naver.com

${ }^{2}$ Department of Biological Engineering, Konkuk University, 120

Neungdong-ro, Gwangjin-gu, Seoul 05029, Republic of Korea

Full list of author information is available at the end of the article
} 


\section{Background}

External stimuli, including the sun's rays as well as direct and continuous exposure of keratinocytes to the external environment, lead to oxidative stress and skin aging. When the skin is in a continuous oxidative state with slow recovery, it becomes rough and dull, which causes skin aging characterized by loss of elasticity and wrinkles (Agarwal et al. 1988; Wong et al. 2007). Therefore, improving the body's antioxidant system is important for protecting keratinocytes and delaying cellular aging (Applegate et al. 1995).

Skin aging can be divided into two classes: intrinsic aging caused by natural genetics and extrinsic aging caused by exposure to the external environment (Naylor et al. 2011). Short-wavelength ultraviolet light (UVB) induces the production of matrix metalloproteinases (MMPs), which harm the skin (Pygmalion et al. 2010). The primary function of MMPs is to break down proteins and enzymes in the extra cellular matrix (ECM) (Egeblad and Werb 2002). Thus, MMPs have a destructive effect on the ECM and cause a decrease in fibrous collagen (Scharffetter-Kochanek et al. 2000). UCB passes through the skin keratin, causes DNA damage, and interacts with photosensitizers and chromatophores to induce oxidative stress (Ma et al. 2001). Consequently, UVB promotes the production of activator protein-1 (AP-1) and vitalization of nuclear factor kappa-light-chain-enhancer of activated $B$ cells and induces the production of reactive oxygen species (ROS) on cell surface receptors, such as mitogen-activated kinases (MAPK) (Xu and Fisher 2005; Jiang et al. 2006). As such, UV is a major cause of skin aging. To delay aging, continuous research and development have been conducted in a variety of fields to normalize the signal systems within skin cells and prevent harm caused by UV and external stimuli.

Syringic acid, a type of phenolic compound, can be obtained through the selective hydrolysis of eudesmic acid containing 20\% sulfuric acid (Bogert and Ehrlich 1919). It is contained in large amounts in oils of acai berries and other fruits (Pacheco-Palencia et al. 2008). Syringic acid is isolated from medicinal plants and biosynthesized through the shikimic acid pathway (Andrade et al. 2001; De Heredia et al. 2001; Dawidar et al. 2000). Studies on the selective effects of syringic acid (Shim et al. 1995; Goldberg et al. 1999; Ferguson 2001), such as strong anticancer and anti-inflammatory effects (Lü et al. 1998; Sun et al. 2002; Rekha et al. 2014), antioxidant effects (Srinivasn et al. 2014), and DPPH radical-scavenging activity, have been conducted. Compared with traditional chemical agents, natural ingredients extracted from plants are known to be less toxic to normal cells but are selectively toxic to cancer cells. Accordingly, there has been a growing interest in the mechanisms and extracted components of natural active compounds (Shim et al. 1995).

The present study investigated the antioxidant effects of syringic acid on MMP expression alteration and MMP production control through the AP-1 mechanism in human keratinocytes exposed to UVB radiation and confirmed the protective effects of syringic acid against cell damage and its potential as a cosmetic component.

\section{Methods \\ Cell culture and sample treatment Cell culture}

A human keratinocyte $(\mathrm{HaCaT})$ cell line was obtained from American Type Culture Collection (USA) and cultured Dulbecco's modified Eagle's medium (Hyclone, USA) containing $\mathrm{HaCaT}$ cells in $10 \%$ fetal bovine serum (Hyclone) and $1 \%$ penicillin/streptomycin (penicillin $100 \mathrm{IU} / \mathrm{mL}$, streptomycin $100 \mu \mathrm{g} / \mathrm{mL}$; Invitrogen, USA) and incubated at $37^{\circ} \mathrm{C}$ in $5 \% \mathrm{CO}_{2}$.

\section{Syringic acid treatment}

Syringic acid was purchased from Sigma-Aldrich (USA) in refined powder form and was dissolved in dimethyl sulfoxide (Sigma-Aldrich) for the experiment. After culturing $\mathrm{HaCaT}$ cells $\left(1 \times 10^{6}\right.$ cells/well $)$ in culture dishes for $24 \mathrm{~h}$, syringic acid was added to the medium, and the culture was incubated for $6 \mathrm{~h}$. The cells were then irradiated with a UVB lamp (UVP, USA). UVB wavelengths were measured using a USB 2000 fiberoptic spectrometer system (Ocean Optics, USA). To investigate the effects of UVB on $\mathrm{HaCaT}$ cells, the medium was removed from the culture plate and washed with phosphate-buffered saline (PBS; $\mathrm{pH}$ 7.4). To prevent the cells from drying, 1-mL PBS was added to the washed $\mathrm{HaCaT}$ cells, which were then irradiated with UVB with the lid open. After UBS irradiation, PBS was removed, fresh medium was added, and the cells were further cultured for $24 \mathrm{~h}$.

\section{Measurement of cell viability}

The cell viability was measured using the principles of the water-soluble tetrazolium salts (WST)- 1 assay, which measures the absorbance of formazan, a chromogenic material obtained by the reaction of mitochondrial dehydrogenase and soluble tetrazolium salts. The cells were inoculated into 96-well plates at a concentration of $3 \times 10^{3}$ cells/well in $100-\mu \mathrm{L}$ amounts and incubated for $24 \mathrm{~h}$. The cells were then treated with syringic acid at concentrations of $1,2,5$, and $10 \mu \mathrm{M}$ and incubated for another $24 \mathrm{~h}$ after exposure to UVB. Subsequently, 10$\mu \mathrm{L}$ aliquots of EZ-Cytox cell viability assay kit reagent (ItsBio, Korea) was added to the cell culture plates. After 1-h incubation, a microplate reader (Bio-Rad, USA) was 
used to measure the absorbance at $490 \mathrm{~nm}$ to determine the cell viability; this process was repeated thrice to derive the mean and standard deviation of cell viability.

\section{RNA extraction and CDNA production}

After extracting RNA for a quantitative analysis of the changes in gene expression pattern in $\mathrm{HaCaT}$ cells due to syringic acid, cDNA was synthesized, and the expression level of the desired gene was determined through quantitative real-time polymerase chain reaction (qRTPCR). After dissolving the incubated cells in TRIzol reagent (Invitrogen, USA), 0.2-mL chloroform (Biopure, Canada) was added, and the cells were kept at room temperature before centrifuging at $12000 \mathrm{rpm}$ at $4{ }^{\circ} \mathrm{C}$ for $20 \mathrm{~min}$. Subsequently, the supernatant fluid, including mRNA from the infranatant liquid with protein, was separated, and $0.5-\mathrm{mL}$ isopropanol was added to it. The cells were kept at room temperature for $10 \mathrm{~min}$ and then centrifuged at $12000 \mathrm{rpm}$ at $4{ }^{\circ} \mathrm{C}$. After precipitating the RNA, it was washed with $75 \%$ ethanol, ethanol was removed, and the RNA was dried in room temperature. The dried mRNA was dissolved in diethylpyrocarbonate (DEPC; Biopure) water for use in the experiment, and only the extracted RNA that exceeded the purity level of 260/280 $\mathrm{nm}$ (1.8 ratio), as determined using nanodrop (Maestrogen, USA), was used in the experiment. After obtaining $10 \mu \mathrm{L}$ of $1-\mu \mathrm{g}$ RNA, 0.5 -ng oligo dT18 with DEPC water was added in a PCR tube and kept at $70{ }^{\circ} \mathrm{C}$ for 10 min. After inducing RNA denaturation, RNA was incubated with M-MLV reverse transcriptase (Enzynomics, Korea) at $37{ }^{\circ} \mathrm{C}$ for $1 \mathrm{~h}$ to synthesize cDNA.

\section{Measurement of gene expression}

qRT-PCR is used to measure the amount of amplification products by measuring the real-time fluorescence of fluorescent material, such as double-strand DNA SYBR green, bound by PCR products. The threshold at which fluorescence can be detected was set to the threshold cycle (ct), and after measuring the number of cycles that were needed to reach the $\mathrm{ct}$, the difference in expression levels was determined. If the expression level is high, ct is reached quickly. As the number of cycles decreases, expression decreases. Therefore, the difference in one cycle results in twice the expression.

qRT-PCR was performed using Linegene $\mathrm{K}$ (BioER, China) and mixing $0.2 \mu \mathrm{M}$ of primers with $50 \mathrm{mM} \mathrm{KCl}$, $20 \mathrm{mM}$ Tris/ $\mathrm{HCl}(\mathrm{pH}$ 8.4), $0.8 \mathrm{mM}$ dNTP, $0.5 \mathrm{U}$ Extaq DNA polymerase, $3 \mathrm{mM} \mathrm{MgCl}$, and $1 \times$ SYBR green (Invitrogen) in a PCR tube. The validity of PCR was verified by performing a melting curve analysis. The expression of each gene was normalized to $\beta$-actin expression in a comparative analysis. The primers used in the experiments were as follows (Table 1).

\section{Measurement of AP-1 promoter activity}

AP-1 promoter luciferase assay was used to determine the effects of syringic acid on the transcriptional activity of AP-1 promoter. In this experiment, expression was confirmed after transfection using a vector (BPS Bioscience, CA, USA) in which AP-1-responsive elements were located in front of the luciferase gene. The cells were placed in 96-well culture dishes at a concentration of $3 \times 10^{4}$ cells/well and incubated for $24 \mathrm{~h}$. After stabilizing the cells, $1 \mu \mathrm{L}$ of the reporter gene was mixed with $15 \mu \mathrm{L}$ of the cell culture medium. Subsequently, after adding $0.35-\mu \mathrm{L}$ lipofectamine 2000 to $15-\mu \mathrm{L}$ cell culture medium, diluent DNA and lipofectamine 2000 diluent were mixed and reacted at room temperature for $25 \mathrm{~min}$. After the mixture was added to the cell plates in $30-\mu \mathrm{L}$ amounts, it was incubated for $24 \mathrm{~h}$ and treated with reagents and stimuli. After an additional $24 \mathrm{~h}$ of incubation, the transcriptional activity of AP-1 promoter was measured.

\section{Production of MMP-1 and procollagen type I}

The enzyme-linked immunosorbent assay (ELISA) is an enzyme-substrate binding assay that uses antigenspecific reactivity to detect an antigen. This method was used to measure the production of MMP-1 and procollagen type I. After seeding, the cells were incubated for $24 \mathrm{~h}$. After stimulating the cells with the

Table 1 List of primers used in this study

\begin{tabular}{lll}
\hline Gene & Forward primer & Reverse primer \\
\hline SOD1 & GGGAGATGGCCCAACTACTG & CCAGTTGACATGCAACCGTT \\
GPX1 & TTCCCGTGCAACCAGTTG & GGACGTACTTGAGGGAATTCAGA \\
CAT & ATGGTCCATGCTCTCAAACC & CAGGTCATCCAATAGGAAGG \\
MMP1 & TCTGACGTGATCCCAGAGAGCAG & CAGGGTGACACCAGTGACTGCAC \\
MMP2 & GGAATGCCATCCCCGATAAC & CAGCCTAGCCAGCCAGTCGGATTT \\
MMP9 & GGGCTTAGATCATTCCTCAGTGCC & GAAGATGTTCACGTGGAGGCATC \\
C-Fos & GGAAGGGACGGAATAAGATG & GCTGCCAAAATAAACTCCAG \\
c-Jun & TCCTATGACGATGCCCTCAAC & GTGTTCTGGCTGTGCAGTC \\
\hline
\end{tabular}


sample, the cells were cultured for another $24 \mathrm{~h}$, and the cell culture medium was then separated. ELISA of MMP-1 and procollagen were performed using the MMP-1 ELISA kit (QIA55; Merck \& Co., Inc., USA) and the procollagen type I C-peptide enzyme immunoassay kit (MK 101; Takara, Japan). A 100- $\mu \mathrm{L}$ aliquot of cell culture medium was added to the surface of each plastic cell culture dish well fixated with MMP-1 monoclonal antibody and incubated at room temperature for $2 \mathrm{~h}$. The cells were washed five times with $1 \times$ washing buffer, $100-\mu \mathrm{L}$ horseradish peroxide-conjugated anti-MMP-1 antibody was added, and the cells were incubated at room temperature for $1 \mathrm{~h}$. Subsequently, $100-\mu \mathrm{L}$ of $3,3^{\prime}, 5,5^{\prime}$-tetramethylbenzidine (TMB) substrate was added and incubated in a dark room at room temperature for $30 \mathrm{~min}$. The absorbance was measured at $450 \mathrm{~nm}$.

Subsequently, $100 \mu \mathrm{L}$ of the culture medium was dispensed into the anti-procollagen type I C-peptide (PIP) monoclonal antibody-coated plate and kept at room temperature for $2 \mathrm{~h}$. The medium was washed five times with $1 \times$ washing buffer and procollagen type-ICpeptide (anti-PIP) monoclonal antibody, which was labeled with peroxidase, and hydrogen peroxide used to catalyze the dehydrogenation of substrates was added and reacted for $3 \mathrm{~h}$. After adding 100- $\mu \mathrm{L}$ TMB substrate and incubating at room temperature for $15 \mathrm{~min}$, the absorbance was measured at $450 \mathrm{~nm}$.

\section{Statistical analysis}

All experiments were independently repeated $\geq$ three times under the same conditions to obtain the experimental results. The results of each experiment were analyzed using the non-paired Student's $t$ test. The $p$ value was calculated, and any value $<0.05$ was considered to indicate statistical significance.

\section{Results}

To examine the cytotoxicity of syringic acid and cytoprotective effects against UVB, $\mathrm{HaCaT}$ cells were treated with syringic acid at concentrations of $1,2,5$, 10 , and $20 \mu \mathrm{M}$ and incubated for $25 \mathrm{~h}$ before WST-1 assay. We found that $1 \mu \mathrm{M}$ of syringic acid resulted in a $105 \%$ cell survival rate, $2 \mu \mathrm{M}$ resulted in a $108 \%$ cell survival rate, $5 \mu \mathrm{M}$ resulted in a $104 \%$ cell survival rate, $10 \mu \mathrm{M}$ resulted in a $96 \%$ cell survival rate, and $20 \mu \mathrm{M}$ resulted in an $88 \%$ cell survival rate (Fig. 1). To investigate the cytoprotective effects of syringic acid against cell damage caused by UVB, the $\mathrm{HaCaT}$ cells were treated with syringic acid at concentrations of 1 , 2,5 , and $10 \mu \mathrm{M}$ and irradiated with $15 \mathrm{~mJ} / \mathrm{cm}^{2} \mathrm{UVB}$. Compared with the cell survival rate of $72 \%$ for the control group irradiated with UVB, that of cells treated with $1 \mu \mathrm{M}$ of syringic acid increased to $78 \%$, that of cells treated with $2 \mu \mathrm{M}$ of syringic acid increased to $88 \%$, that of the cells treated with $5 \mu \mathrm{M}$ of syringic acid increased to $92 \%$, and that of cells treated with $10 \mu \mathrm{M}$ of syringic acid increased to $102 \%$ (Fig. 2).

In addition, we confirmed that $\mathrm{ROS}$ in $\mathrm{HaCaT}$ cells harmed by UVB were eliminated by syringic acid. After ROS produced by UVB were fluorescently stained with DCF-DA, flow cytometry (BD Biosciences, USA) was used to measure the change in values. It revealed that $15 \mathrm{~mJ} / \mathrm{cm}^{2}$ UVB caused a 2.6-fold increase in ROS, but after treatment with syringic acid at concentrations of 2 , 5 , and $10 \mu \mathrm{M}$, the ROS levels in the UVB-exposed $\mathrm{HaCaT}$ cells decreased by 2.1-, 1.5-, and 1.2-fold, respectively. In particular, $10 \mu \mathrm{M}$ of syringic acid was more effective in eliminating ROS than the same concentration of $\mathrm{N}$-acetyl-L-cysteine (NAC; Calbiochem, USA), which acts as a ROS scavenger (Fig. 3). We used qRT-PCR to verify that SOD1 mRNA, which decreased in response to UVB, had an antioxidant effect of superoxide anion radical elimination due to UVB and found that exposure to $15-\mathrm{mJ} / \mathrm{cm}^{2} \mathrm{UVB}$ caused the expression

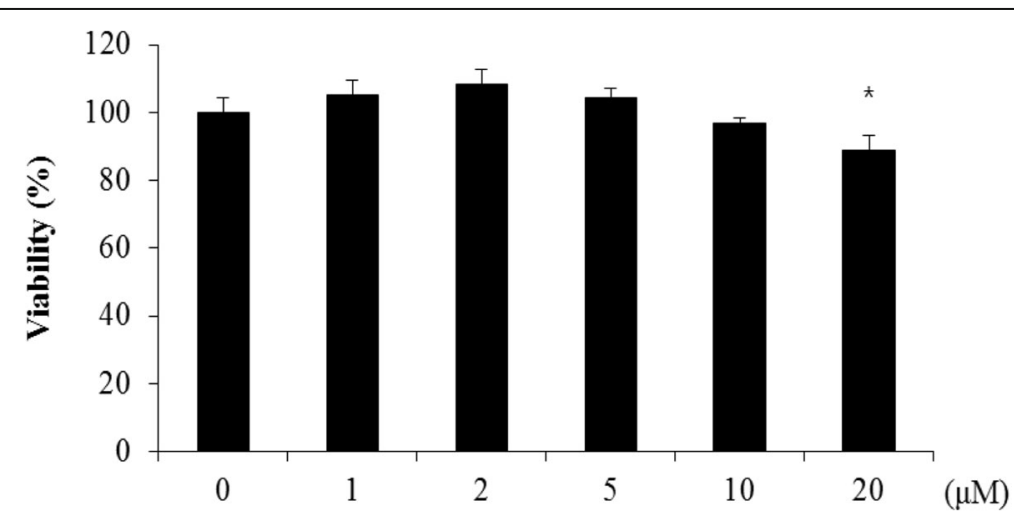

Fig. 1 Cellular toxicity of syringic acid in HaCaTs. Effect of syringic acid on HaCaT cell viability at the indicated concentrations. Results are expressed as the mean \pm SD in triplicate; ${ }^{*} p<0.05$ vs the non-treated group 


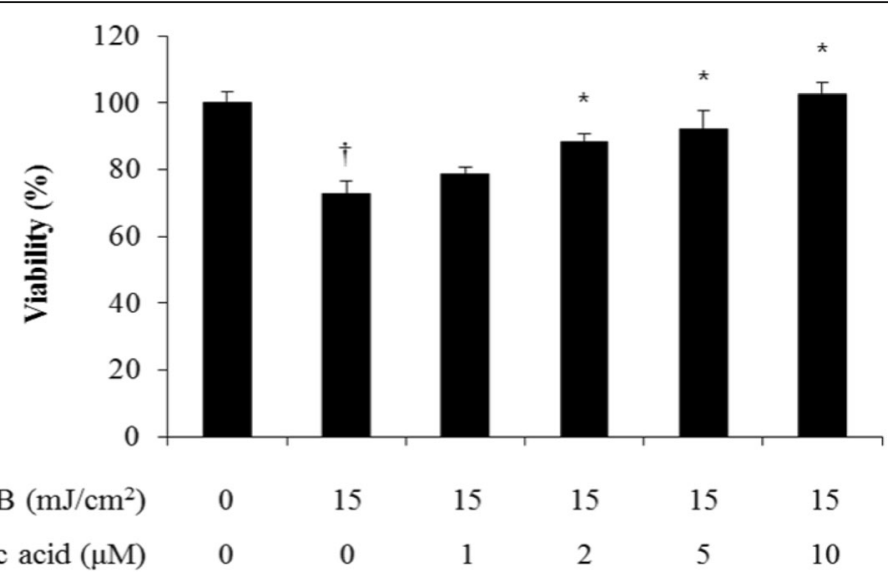

Fig. 2 Effect of syringic acid on the viability of UVB-irradiated HaCaTs. Data are expressed as the mean \pm SD in triplicate; $+p<0.05$ vs the non-treated group, ${ }^{*} p<0.05$ vs the UVB-treated group without syringic acid

level of SOD1 to decrease 0.7 -fold, but after treatment with 2,5 , and $10 \mu \mathrm{M}$ of syringic acid, the SOD1 mRNA expression after exposure to $15 \mathrm{~mJ} / \mathrm{cm}^{2}$ UVB increased 0.9-, 1.1-, and 1.2-fold, respectively (Fig. 4). We also used qRT-PCR to verify that GPX1 mRNA, which decreased in response to UVB, had an antioxidant effect of superoxide anion radical elimination caused by UVB and found that $15-\mathrm{mJ} / \mathrm{cm}^{2}$ UVB caused the expression level of GPX1 to decrease 0.2-fold, but after treatment with 2, 5 , and $10 \mu \mathrm{M}$ of syringic acid, the SOD1 mRNA expression after exposure to $15 \mathrm{~mJ} / \mathrm{cm}^{2}$ UVB increased 0.8-, 1.4-, and 2.2-fold, respectively (Fig. 5). In this experiment, qRT-PCR was used to determine whether catalase (CAT) mRNA, which decreased in response to UVB, could be recovered to some extent by syringic acid and found that $15-\mathrm{mJ} / \mathrm{cm}^{2}$ UVB caused the expression level of CAT mRNA to decrease 0.2-fold, but after treatment with 2, 5, and $10 \mu \mathrm{M}$ of syringic acid, CAT mRNA expression after exposure to $15 \mathrm{~mJ} / \mathrm{cm}^{2}$ UVB increased 0.4-, 0.7-, and 0.9-fold, respectively (Fig. 6).

To examine the changes in MMP expression and MMP-1 production caused by syringic acid through the AP-1 mechanism, qRT-PCR was used to determine the degree of reduction in c-Jun and c-Fos mRNA expression due to syringic acid after their increase in response to UVB. Our results revealed that $15-\mathrm{mJ} / \mathrm{cm}^{2}$ UVB caused a 2.1-fold increase in the expression level of c-Jun mRNA, but after treatment with 2, 5, and $10 \mu \mathrm{M}$ of syringic acid, c-Jun mRNA expression decreased 1.9-, 1.3-, and 1.1-fold, respectively. Exposure

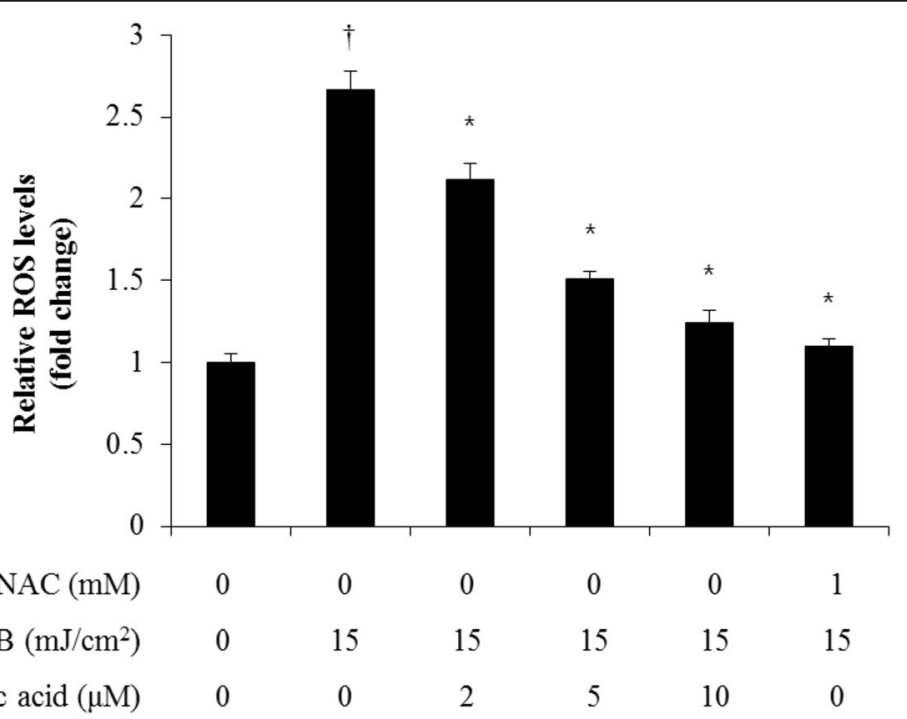

Fig. 3 ROS scavenging effect of syringic acid in UVB-irradiated HaCaTs. Results are expressed as the mean \pm SD in triplicate; $t p<0.05$ vs the non-treated group, ${ }^{*} p<0.05$ vs the UVB-treated group without syringic acid 


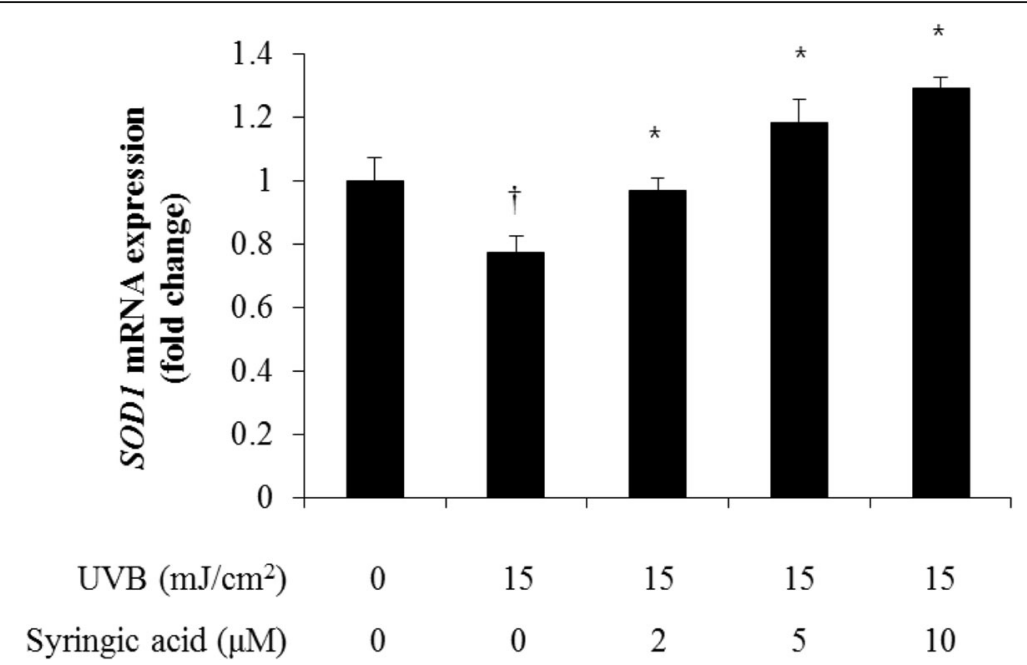

Fig. 4 Effect of syringic acid on the SOD1 mRNA expressions in UVB-irradiated HaCaTs. Data are represented as the mean \pm SD in triplicate; $t p<$ 0.05 vs the non-treated group, ${ }^{*} p<0.05$ vs the UVB-treated group without syringic acid

to $15-\mathrm{mJ} / \mathrm{cm}^{2} \mathrm{UVB}$ caused a 1.2 -fold increase in the expression level of $c$-Fos mRNA, but after treatment with 2,5 , and $10 \mu \mathrm{M}$ of syringic acid, $c$-Fos mRNA expression after exposure to $15 \mathrm{~mJ} / \mathrm{cm}^{2} \mathrm{UVB}$ decreased 1.1-, 1.0-, and 0.9-fold, respectively (Fig. 7). In this experiment, AP-1 luciferase reporter vector (BPS Bioscience, CA, USA) with AP-1-responsive elements located in front of luciferase in the promoter region was used for transfection before luciferase gene expression was measured via luciferin luminescence measurement. The results confirmed the transcriptional activity of the transcription factor AP-1 promoter, which affects skin aging via inflammation, immune response, cell proliferation, and collagen degradation. The luminescence of luciferin increased twofold due to $15-\mathrm{mJ} / \mathrm{cm}^{2} \mathrm{UVB}$, but after syringic acid treatment at concentrations of 2,5 , and $10 \mu \mathrm{M}$, it decreased 1.5-, 1.2-, and 1.0-fold, respectively, after exposure to $15 \mathrm{~mJ} / \mathrm{cm}^{2} \mathrm{UVB}$. We confirmed that the decrease in the luminescence of luciferin due to syringic acid was concentration-dependent. This finding confirmed that syringic acid inhibited the transcription activity of the transcription factor AP-1 promoter, which affects skin aging via skin inflammation,

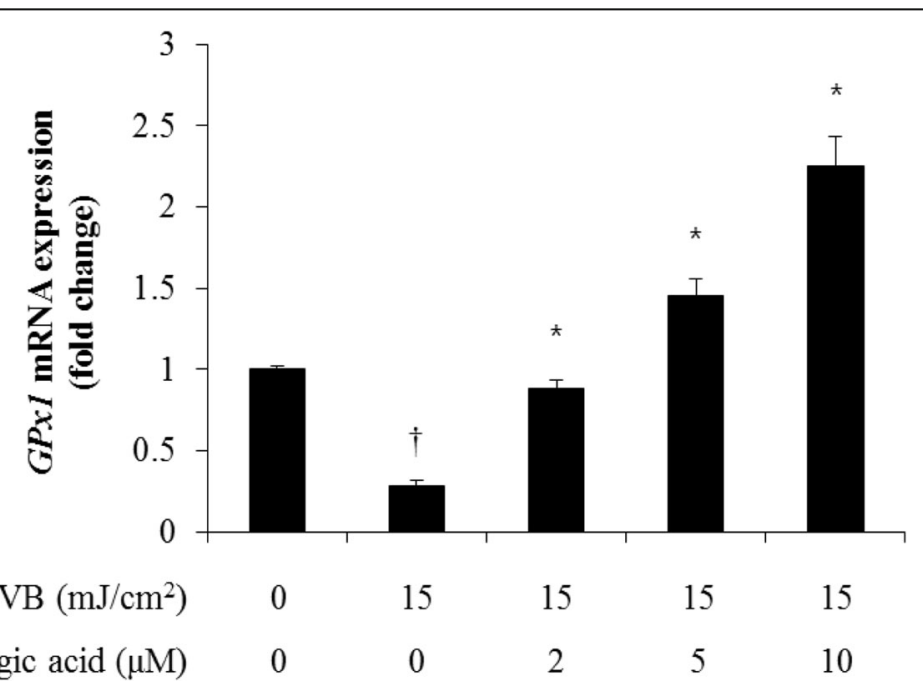

Fig. 5 Effect of syringic acid on GPX1 mRNA expressions in UVB-irradiated HaCaTs. Results are expressed as the mean \pm SD in triplicate; $† p<0.05$ vs the non-treated group, ${ }^{*} p<0.05$ vs the UVB-treated group without syringic acid 


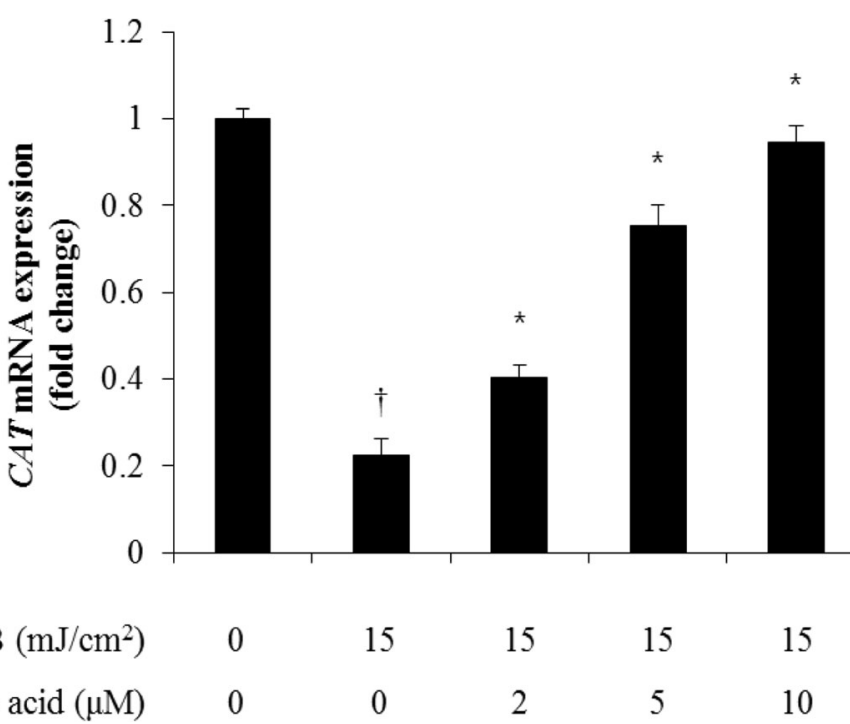

Fig. 6 Effect of syringic acid on CAT mRNA expressions in UVB-irradiated HaCaTs. Data are expressed as the mean \pm SD in triplicate; $\uparrow p<0.05$ vs the non-treated group, ${ }^{*} p<0.05$ vs the UVB-treated group without syringic acid

immune response, cell proliferation, and collagen degradation (Fig. 8).

\section{Change in MMP mRNA expression}

The effect of syringic acid on $M M P-1, M M P-2$, and $M M P-9$ expressions was confirmed by qRT-PCR. It demonstrated that after exposure to $15-\mathrm{mJ} / \mathrm{cm}^{2} \mathrm{UVB}$, the expression levels of $M M P-1, M M P-2$, and $M M P-9$ increased 2.5, 4.3, and 1.8-fold, respectively, but after treatment with 2,5 , and $10 \mu \mathrm{M}$ of syringic acid, the $M M P-1$ mRNA expression after exposure to $15-\mathrm{mJ} / \mathrm{cm}^{2}$ UVB decreased 1.9-, 1.4-, and 1.06-fold, respectively. Because of syringic acid treatments at concentrations of 2, 5, and $10 \mu \mathrm{M}, M M P-2$ mRNA expression after exposure to $15-\mathrm{mJ} / \mathrm{cm}^{2} \mathrm{UVB}$ decreased 3.4-, 2.1-, and 0.9 -fold, respectively, in a concentration-dependent manner, and MMP-9 mRNA expression decreased to 1.0-, 0.9-, and 0.8-fold, respectively, in a concentrationdependent manner (Fig. 9). ELISA was used to determine the effects of syringic acid on the production of MMP-1, which is a collagen inhibitor that increases in response to UVB. It demonstrated that exposure to 15$\mathrm{mJ} / \mathrm{cm}^{2}$ UVB caused a 1 - to 1.9 -fold increase in MMP1 production, but after treatment with 2,5 , and $10 \mu \mathrm{M}$ of syringic acid, MMP-1 production after exposure to $15-\mathrm{mJ} / \mathrm{cm}^{2}$ UVB decreased 1.8-, 1.5-, and 1.3-fold, respectively (Fig. 10). Therefore, it seems that syringic acid has anti-aging effects in $\mathrm{HaCaT}$ cells.

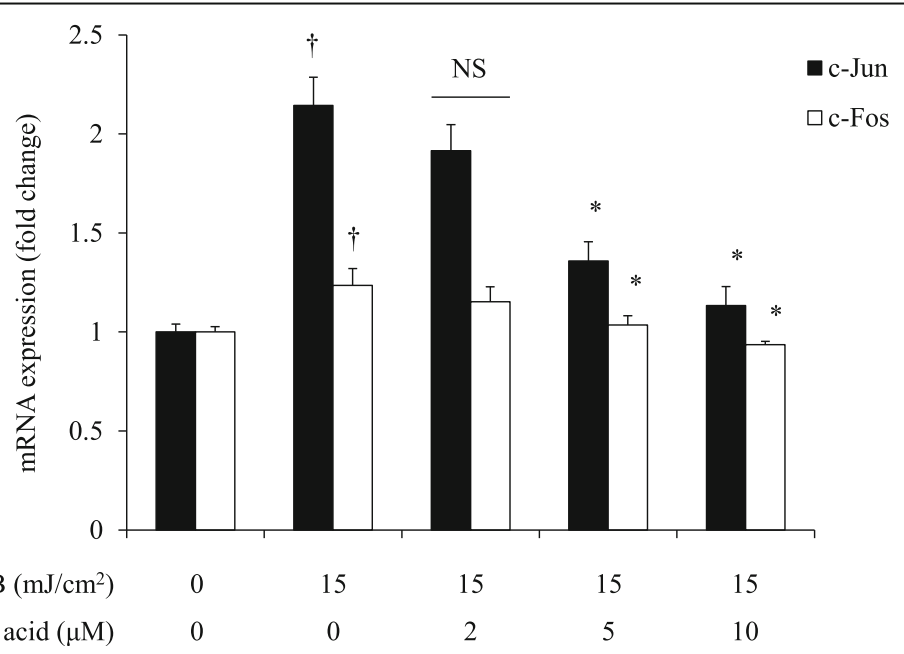

Fig. 7 Effect of syringic acid on c-Jun and c-Fos mRNA expressions in UVB-irradiated HaCaTs. Results are expressed as the mean \pm SD in triplicate; $t p<0.05$ vs the non-treated group, ${ }^{*} p<0.05$ vs the UVB-treated group without syringic acid. NS means not significance 


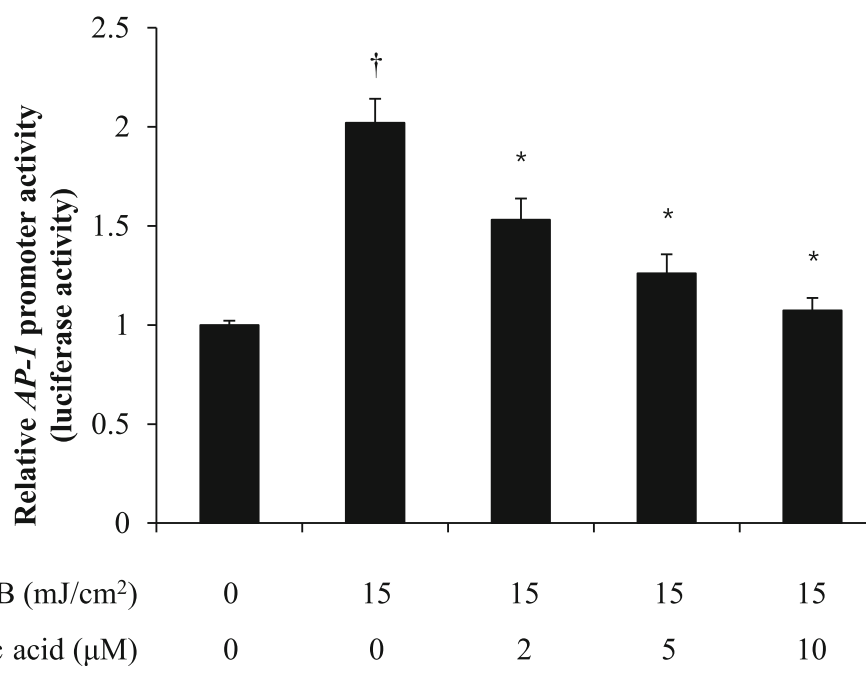

Fig. 8 Effect of syringic acid on AP-1 promoter activity in UVB-irradiated HaCaTs. Data are expressed as the mean \pm SD in triplicate; $† p<0.05$ vs the non-treated group, ${ }^{*} p<0.05$ vs the UVB-treated group without syringic acid

\section{Discussion}

This study demonstrated that $10 \mu \mathrm{M}$ was the highest concentration of syringic acid used in the UVB cytoprotective experiments. We found that the cytoprotective effects of syringic acid and the cell survival rates in $\mathrm{HaCaT}$ harmed by UVB were concentration-dependent.

The oxidation inhibition effects of syringic acid on $\mathrm{HaCaT}$ cells harmed by UVB were examined. ROS decreased in $\mathrm{HaCaT}$ after pretreatment with syringic acid and also confirmed that syringic acid increased the expression of $S O D 1$ mRNA, an antioxidant gene, in a concentration-dependent manner. And found that syringic acid increased GPX1 expression in a concentration-dependent manner, which reduced oxygen-free radicals and suppressed cellular aging. This experiment confirmed the antioxidative effects of GPX1, where syringic acid increased the concentration of CAT mRNA, an antioxidant gene, in a concentrationdependent manner.

In this study, c-Jun and c-Fos mRNA, which are involved in the expression of proteins, such as MMP, increased in response to UVB but decreased in response to syringic acid in a concentration-dependent manner. Therefore, syringic acid is considered to have anti-aging effects in human keratinocytes, confirming the transcriptional activity of the transcription factor, AP-1 promoter, which affects skin aging due to inflammation, immune response, cell proliferation, and

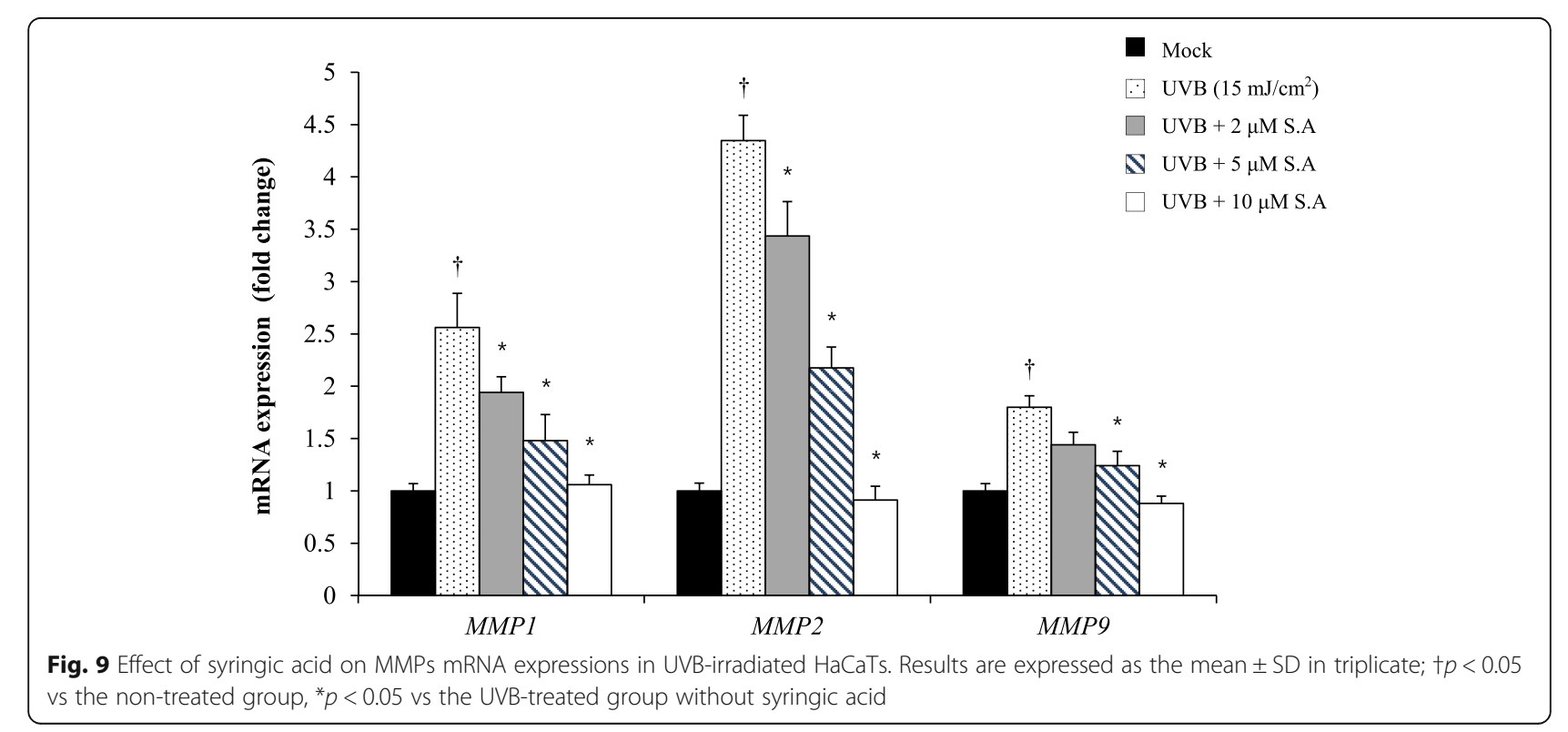




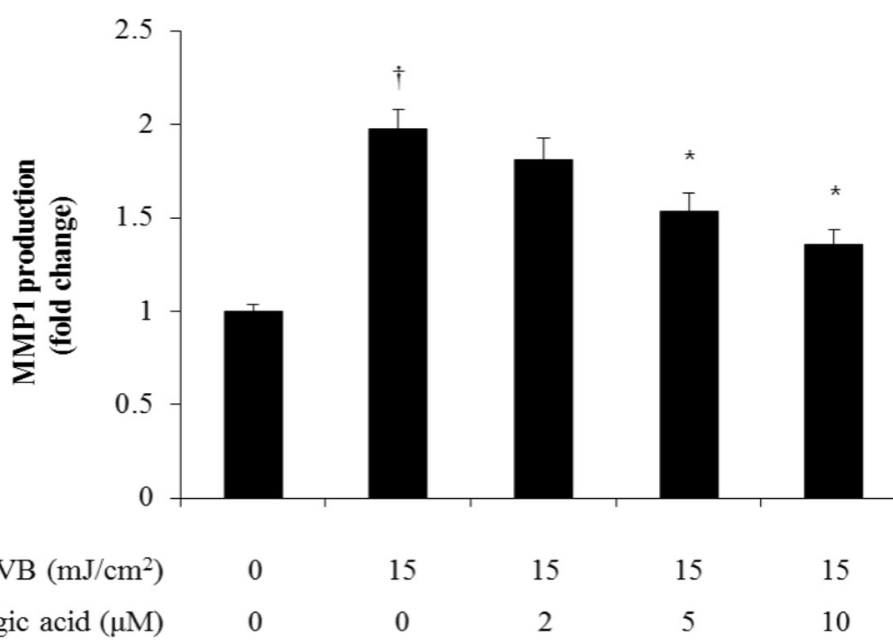

Fig. 10 Effect of syringic acid on MMP-1 production in UVB-irradiated HaCaTs. Data are represented as the mean \pm SD in triplicate; $t p<0.05$ vs the non-treated group, ${ }^{*} p<0.05$ vs the UVB-treated group without syringic acid

collagen degradation. Therefore, syringic acid appeared to be an effective anti-aging agent in human keratinocytes.

Proteinases, such as MMP-1, play a crucial role in skin aging by abnormally suppressing collagen in dermal tissues (Chen et al. 2008). In the present study, we confirmed that syringic acid decreased the production of collagen-inhibiting enzyme MMP-1 in a concentrationdependent manner. Thus, syringic acid has an anti-aging effect in the human keratinocyte cell line $\mathrm{HaCaT}$.

Therefore syringic acid was shown to be involved in altering MMP expression and controlling MMP-1 production through the AP-1 mechanism. Thus, the antioxidant and anti-aging effects of syringic acid increased the survival rate of $\mathrm{HaCaT}$ cells damaged by ultraviolet $B$, suggesting that it can be used as a natural phytochemical in cosmetic products.

\section{Conclusion}

Most studies related to syringic acid have focused on its antioxidant and anti-inflammatory roles in the fields of food, medicine, pharmacy, and life sciences. No study has been conducted on its role in anticancer treatments or cosmetics. In particular, no research on the effects of syringic acid in human keratinocytes has been published. The present study investigated the effects of syringic acid, which has been shown to protect against cell damage via anti-inflammatory, antioxidant, and anticancer effects. It examined antioxidative effects of syringic acid in $\mathrm{HaCaT}$ cells exposed to UVB and the effect on $M M P$ expression alteration and MMP production control through AP-1 regulation. Syringic acid was tested for its cytoprotective effect and its potential as a cosmetic ingredient. Syringic acid was shown to be involved in
MMP gene expression and MMP production control through AP-1 regulation, thereby protecting human keratinocytes from damage and restoring the survival rate of the cells harmed by UVB. Syringic acid was shown to have antioxidant and anti-aging effects; therefore, it can potentially be used as a natural phytochemical ingredient in cosmetic products.

\section{Abbreviations}

Anti-PIP: Procollagen type-IC-peptide; AP-1: Activator protein-1; CAT: Catalase; c-Fos: Cellular-Fujinami OsteoSarcoma virus; c-Jun: Cellular-Jun;

DEPC: Diethylpyrocarbonate; DMEM: Dulbecco's modified Eagle medium; FBS: Fetal bovine serum; GPX: Glutathione peroxidase; HaCaT: Human keratinocyte; MAPK: Mitogen-activated kinases; MMPs: Matrix metalloproteinases; QRT-PCR: Quantitative real-time polymerase chain reaction; ROS: Reactive oxygen species; SOD1: Superoxide dismutase 1; UV: Ultraviolet; WST: Water-soluble tetrazolium salts

\section{Acknowledgements}

Not applicable

\section{Funding}

Not applicable

Availability of data and materials Not applicable.

\section{Authors' contributions}

Both authors contributed to all the research background such as the experiments, data collection, and statistical analysis as well as manuscript draft. Both authors read and approved the final manuscript.

Ethics approval and consent to participate Not applicable

Consent for publication

Not applicable

Competing interests

The authors declare that they have no competing interests. 


\section{Publisher's Note}

Springer Nature remains neutral with regard to jurisdictional claims in published maps and institutional affiliations.

\section{Author details}

${ }^{1}$ Halla University, 28, Halladae-gil, Heungeop-myeon, Wonju-si, Gangwon-do 25404, Republic of Korea. ${ }^{2}$ Department of Biological Engineering, Konkuk University, 120 Neungdong-ro, Gwangjin-gu, Seoul 05029, Republic of Korea.

Received: 25 September 2017 Accepted: 5 March 2018

Published online: 15 May 2018

\section{References}

Agarwal S, Drysdale BE, Shin HS. Tumor necrosis factor-mediated cytotoxicity involves ADP-ribosylation. J Immunol. 1988;140(12):4187-92.

Andrade PB, Oliveira BM, Seabra RM, Ferreira MA, Ferreres F, García-Viguera C. Analysis of phenolic compounds in Spanish Albrariño and Portuguese Alvarinho and Loureiro wines by capillary zone electrophoresis and highperformance liquid chromatography. Electrophoresis. 2001;22(8):1568-72.

Applegate LA, Noël A, Vile G, Frenk E, Tyrrell RM. Two genes contribute to different extents to the heme oxygenase enzyme activity measured in cultured human skin fibroblasts and keratinocytes. Photochem Photobiol. 1995;61(3):285-91.

Bogert M, Ehrlich J. The synthesis of certain pyrogallol ethers, including a new acetophenetide derived from the ethyl ether of syringic acid. J Am Chem Soc. 1919;41(5):798-810

Chen W, Kang J, Xia J, Li Y, Yang B, Chen B, Sun W, Song X, Xiang W, Wang X, Wang F, Wan Y, Bi Z. p53-related apoptosis resistance and tumor suppression activity in UVB-induced premature senescent human skin fibroblasts. Int J Mol Med. 2008;21(5):645-53.

Dawidar AM, Ezmiriy ST, Abdel-Mogib M, el-Dessouki Y, Angawi RF. New stilbene carboxylic acid from Convolvulus hystrix. Pharmazie. 2000;55(11):848-9.

De Heredia JB, Torregrosa J, Dominguez JR, Peres JA. Kinetic model for phenolic compound oxidation by Fenton's reagent. Chmosphere. 2001;45(1):85-90.

Egeblad M, Werb Z. New functions for the matrix metalloproteinases in cancer progression. Nat Rev Cancer. 2002;2(3):161-74.

Ferguson LR. Role of plant polyphenols in genomic stability. Mutat Res. 2001; 475(1-2):89-111.

Goldberg DM, Hoffman B, Yang J, Soleas GJ. Phenolic constituents, furans, and total antioxidant status of distilled spirits. J Agric Food Chem. 1999;47(10):3978-85.

Jiang Q, Zhou C, Healey S, Chu W, Kouttab N, Bi Z, Wan Y. UV radiation downregulates Dsg-2 via Rac/NADPH oxidase-mediated generation of ROS in human lens epithelial cells. Int J Mol Med. 2006;18(2):381-7.

Lü W, Shi J, Zhang S, Du Z. Determination of ferulic acid and peoniflorin in siwu decoction prepared by different methods of yellow rice wine. Zhongguo Zhong Yao Za Zhi. 1998;23(9):531-3. 575

Ma W, Wlaschek M, Tantcheva-Poór I, Schneider LA, Naderi L, Razi-Wolf Z, Schüller J, Scharffetter-Kochanek. Chronologicalageing and photoageing of the fibroblasts and thedermal connective tissue. Clin Exp Dermatol. 2001; 26(7):592-9.

Naylor EC, Watson Rachel EB, Sherratt MJ. Molecular aspects of skin ageing. Maturitas. 2011;69(3):249-56.

Pacheco-Palencia LA, Mertens-Talcott S, Talcott ST. Chemical composition, antioxidant properties, and thermal stability of a phytochemical enriched oil from acai (Euterpe oleracea Mart). J Agric Food Chem. 2008;56(12):4631-6.

Pygmalion MJ, Ruiz L, Popovic E, Gizard J, Portes P, Marat X, Lucet-Levannier K, Muller B, Galey JB. Skin cell protection against UVA by Sideroxyl, a new antioxidant complementary to sunscreens. Free Radic Biol Med. 2010; 49(11):1629-37.

Rekha KR, Selvakumar GP, Sivakamasundari RI. Effects of syringic acid on chronic MPTP/probenecid induced motor dysfunction, dopaminergic markers expression and neuroinflammation in C57BL/6 mice. Biomed Aging Pathol. 2014;4(2):95-104.

Scharffetter-Kochanek K, Brenneisen P, Wenk J, Herrmann G, Ma W, Kuhr L, Meewes C, Wlaschek M. Photoaging of the skin from phenotype to mechanisms. Exp Gerontol. 2000;35(3):307-16.

Shim JS, Kang MH, Kim YH, Roh JK, Roberts C, Lee IP. Chemopreventive effect of green tea (Camellia sinensis) among cigarette smokers. Cancer Epidermiol Biomarkers Prev. 1995;4(4):387-911.
Srinivasn S, Muthukumaranb J, Muruganathana U, Venkatesanb RS, Jalaludeenc AM. Antihyperglycemic effect of syringic acid on attenuating the key enzymes of carbohydrate metabolism in experimental diabetic rats. Biomed Prev Nutr. 2014;4(4):595-602.

Sun J, Chu YF, Wu X, Liu RH. Antioxidant and antiproliferative activities of commom fruit. Agric Food Chem. 2002;50(25):7449-54.

Wong T, McGrath JA, Navsaria $H$. The role of fibroblasts in tissue engineering and regeneration. Br J Dermatol. 2007;156(6):1149-55.

Xu Y, Fisher GJ. Ultraviolet (UV) light irradiation induced signal transduction in skin photoaging. J Dermatol Sci Suppl. 2005;1(2):S1-8.

\section{Submit your next manuscript to BioMed Central and we will help you at every step:}

- We accept pre-submission inquiries

- Our selector tool helps you to find the most relevant journal

- We provide round the clock customer support

- Convenient online submission

- Thorough peer review

- Inclusion in PubMed and all major indexing services

- Maximum visibility for your research

Submit your manuscript at www.biomedcentral.com/submit
) Biomed Central 